Grzegorz Sieklucki*, Barbara Bisztyga*

\title{
Uncertainty Mathematical Models of Power Converters
}

\section{Introduction}

Themathematicalmodels of the power converters can be considered in the formof transferfunction $[4,5,6,11,14,15]$

$$
G_{p}(s)=K_{p} e^{-\tau_{0} s} \approx \frac{K_{p}}{\tau_{0} s+1}
$$

For a three-phase system the constant $\tau_{0}$ is regarded as:

- the half of the natural commutation period $\tau_{0}=\frac{1}{12} \cdot \frac{1}{f_{s}}=1.667 \mathrm{~ms}$ (for Europe $f_{s}=50 \mathrm{~Hz}$ ),

- the half of the symmetrical modulation PWM period $\tau_{0}=\frac{1}{2} \cdot \frac{1}{f_{P W M}}$ (typically $f_{P W M}$ is in
the range $5 \div 20 \mathrm{kHz}$ ).

Such a model of the power converter is used in the parametric optimization of the torque and the speed controllers $[7,11,14,20]$, but in the analysis of the control system robustness $[3,8,22,24]$ the use of more accurate mathematical models is necessary. These models should contain the range of the parameters changes which come from construction and work conditions of considered power electronic systems.

The transfer-function models for the three-phase power electronic systems are taken into account in the article.

\section{Three-Phase Thyristor-Controlled Converter}

Thyristor-controlled converters $[4,10,5,11,12,17,19]$ are used as the supply system of the DC motors or rectifiers in the frequency indirect converters (Fig. 1).

* AGH University of Science and Technology, Krakow, Poland 


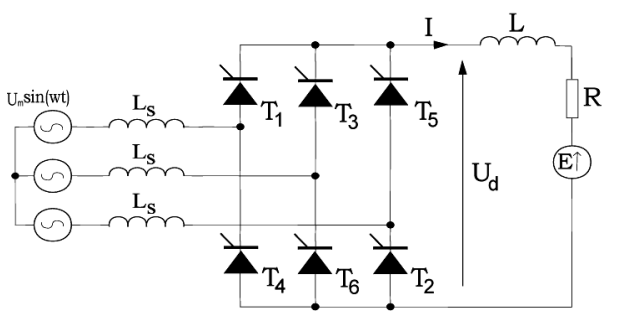

Fig. 1. Three-phase line-commutated converter bridge

The average voltage of the DC side of converter equals $[4,10,5,15,19]$

$$
U_{d}=U_{d 0} \cos (\alpha)-\Delta U_{x}, \quad U_{d 0}=\frac{3 \sqrt{2}}{\pi} U_{T}, \quad \Delta U_{x}=\frac{3}{\pi} \omega L_{s} I
$$

where $\alpha$ is the delay (firing) angle, $U_{T}$ is the line to line rms voltage and $\Delta U_{x}$ is the voltage drop caused by the commutation. $\Delta U_{x}$ voltage is a linear function of the load current $I$ and it can be modelled as a series additional resistor $R_{x}=\frac{3}{\pi} \omega L_{s}$ in the converter output $[4,7,15]$.

Converter control is usually realized through the reference voltage $U_{s}$ which is produced in the control system. For a continuous current conducting the relationship (2) with $U_{s}$ the voltage consideration is presented in Figure 2.

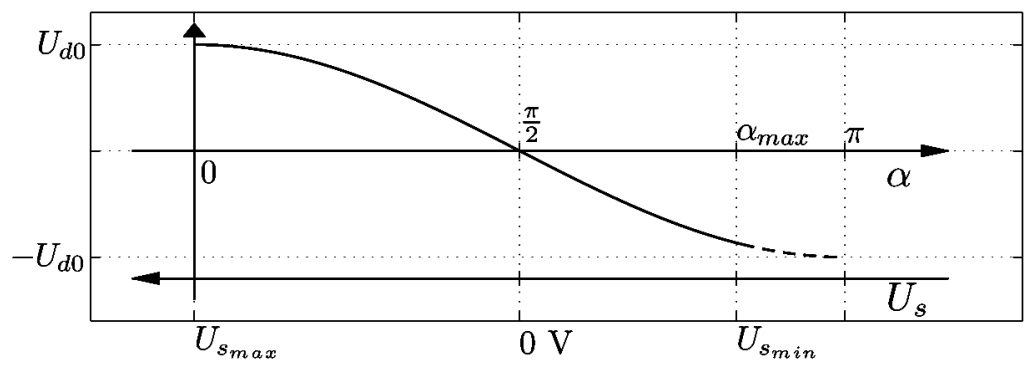

Fig. 2. Transfer characteristic of a thyristor-controlled converter

The output voltage (gain) of the converter is the nonlinear function of the angle $\alpha$ and depends on the shape of a current conducting (continuous or discontinuous).

Thyristor-controlled converter possesses variate time-delay $\tau_{0}$ additionallywhich depends on the the previous value of the angle $\alpha$

$$
\tau_{0}=f\left(\alpha\left(t_{1}\right), \alpha\left(t_{2}\right)\right)
$$

The control process of the converter for various values of the firing angle $\alpha$ is presented in Figure 3. 


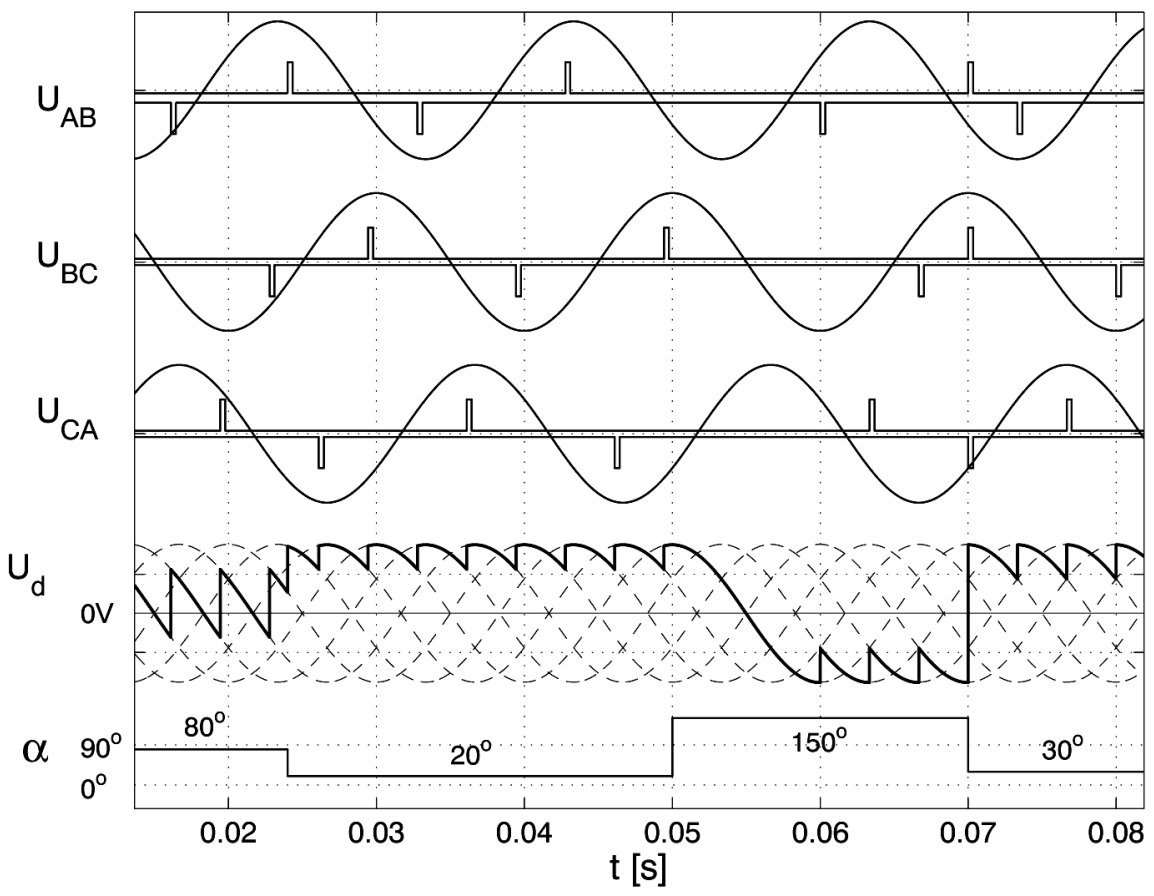

Fig. 3. Output voltage and control signals of three-phase converter with RLE load - continuous current conduction

The results from the presented signals are [15]:

- increasing of the voltage output $U_{d}$ is realized immediately,

- decreasing of the voltage output $U_{d}$ is realized with time-delay and for the large change of the angle $\alpha$ can even lead to $\tau_{0}=8 \mathrm{~ms}$.

The dynamic operation analysis of the thyristor converter is very complicated, so the timedelay model (1) is completed by interval coefficients.

Thus,

$$
\tau_{0} \in[0,0.008]
$$

But from Figure 2 and equation (2) the range of the static gain $K_{p}$ can be determined as

$$
K_{p} \in\left[K_{p \min }, K_{p \max }\right]
$$

Example 1. Continuous current conduction is considered. If $U_{T}=\sqrt{3} \cdot 230 \mathrm{~V}$ and input signal of thyristor converter is in range $\pm 10 \mathrm{~V}$ then firing angle must be computed as

$$
\alpha=-\frac{\pi}{20} U_{S}+\frac{\pi}{2} \quad \text { or } \quad U_{S}=\frac{\pi}{20}\left(\frac{\pi}{2}-\alpha\right)
$$


The function $U_{d}=f\left(U_{S}\right)$ determines the static converter gain for several input signals. Thus, the range of $K_{p}$ is calculated as:

$$
K_{p_{\min }}=\frac{U_{d 0} \cos \left(\alpha_{\min }\right)}{U_{S_{\max }}}=53.8 \frac{\mathrm{V}}{\mathrm{V}}, \quad K_{p_{\max }}=\frac{U_{d 0} \cos \left(\alpha_{x}\right)}{U_{S_{x}}}=84.5 \frac{\mathrm{V}}{\mathrm{V}}
$$

where $U_{S_{x}}, \alpha_{x}$ are small input voltage near $0 \mathrm{~V}$ and corresponding to the firing angle.

\section{Space Vector Modulation for AC Drives}

The structure of a typical three-phase voltage source inverter (VSI) is presented in Figure 4. The transistors IGBT as power electronic switches (PES) are used most frequently which allowus to obtain high switching frequencies (up to $20 \mathrm{kHz}$ ) for the large values of currents.

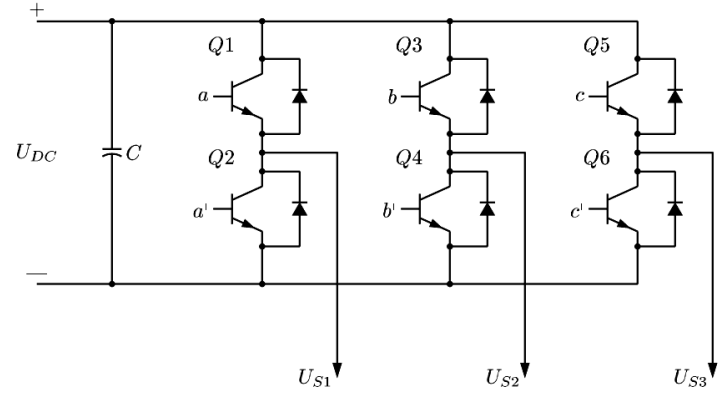

Fig. 4. Voltage source inverter

Control signals $a, a^{\prime}, b, b^{\prime}, c, c^{\prime}$ of PES are assumed as logical $(0,1)$, whereas $U_{S 1}, U_{S 2}, U_{S 3}$ are line to neutral voltages of the motor. There exist 8 different values $(a, b, c)$.

The space vector PWM (SVM) method determines switching sequence of the power transistors $(Q 1 \div Q 6)$. Different input states $(a, b, c)$ create the hexagon of output voltages from additional two zero vector states $\left(U_{000}, U_{111}\right)$. These 8 vectors are called base space vectors: $U_{0}, U_{60}, U_{120}, U_{180}, U_{240}, U_{300}, U_{000}, U_{111}$.

The graphical representation of the space vectors in stationary $(\alpha, \beta)$ frame is presented in Figure 5, where in brackets the control values $(a, b, c)$ are given. Reference voltage $\underline{U}_{S_{\text {ref }}}$ represents the average voltage:

$$
\frac{1}{T_{P W M}} \int_{0}^{T_{P W M}} \underline{U}_{S_{r e f}}(t) d t=\frac{1}{T_{P W M}}\left(T_{1} \underline{U}_{x}+T_{2} \underline{U}_{x \pm 60}\right)
$$

where $T_{1} \mathrm{i} T_{2}$ are turn-on times of neighbouring base vectors $\underline{U}_{x} \mathrm{i} \underline{U}_{S \pm 60}$ respectively and $T_{P W M}$ is the carrier signal period. 


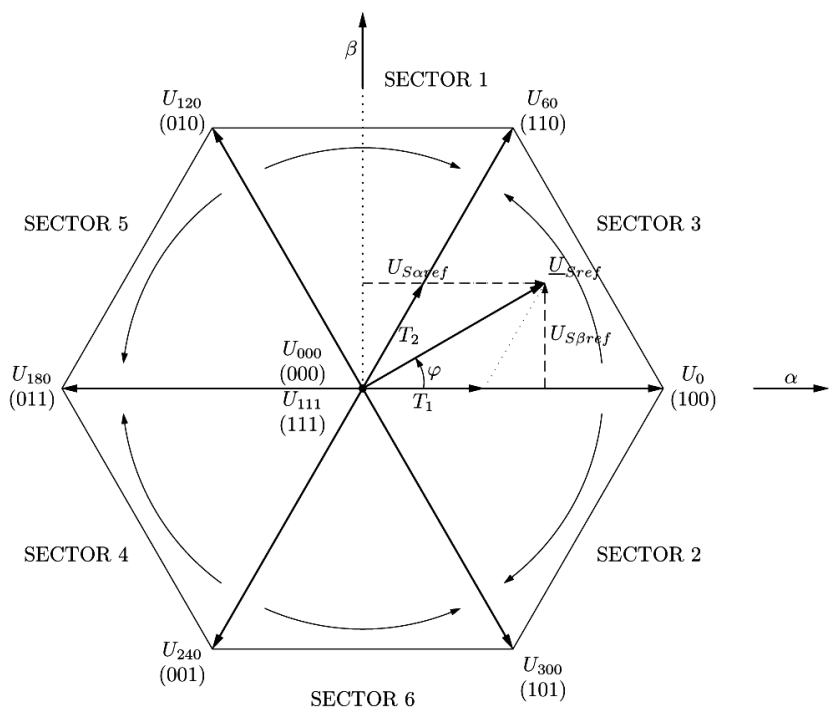

Fig. 5. SVM voltage base vectors in $(\alpha, \beta)$ frame

When $\left|\underline{U}_{S_{\text {ref }}}\right|<U_{D C}$ then between times $T_{1}$ and $T_{2}$ modulation requires $\underline{U}_{000}$ or $\underline{U}_{111}$ vectors in time $T_{0}$. Hence,

$$
T_{1}+T_{2}+T_{0}=T_{P W M}
$$

The times $T_{1}$ and $T_{2}$ can be evaluated in different ways [5, 12, 15, 19, 23] but the obtained results are identical.

In order to prevent short-circuiting in VSI there should be a time-delay between the turnoff of one transistor (e.g. $Q_{1}$ ) and the turn-on of the next (e.g. $Q_{2}$ ). This time-delay $T_{D B}$ is called deadband. In the inverter control systems it is possible to compensate the time $T_{D B}[5]$, so this phenomenon is omitted in the process of creating a mathematical model.

Signals generation example for

$$
\underline{U}_{S_{\text {ref }}}=0.9 U_{D C} e^{j\left(\frac{2 \pi}{9}+k \frac{\pi}{6}\right)}, \quad k=0,1,2,3,4,5
$$

is shown in Figure 6, where the principles presented in Figure 5 and described by relation (6) are used. The voltage $U_{S_{r e f}}$ two times in every period $T_{P W M}$ is introduced. The periods $T_{1}, T_{2}$ and $T_{0}$ are compared with symmetrical carrier signal. The effects of such inverter work is presented in Figures 7 and 8. Based on these waveforms it can be concluded:

$$
\begin{aligned}
& \text { if }\left|\underline{U}_{S_{r e f}}\right|>\frac{1}{2} U_{D C} \quad \text { then } \quad \tau_{0}=\left[0, T_{P W M}\right], \\
& \text { if }\left|\underline{U}_{S_{r e f}}\right|<\frac{1}{2} U_{D C} \text { then } \tau_{0}=\left[T_{P W M}, 3 T_{P W M}\right] .
\end{aligned}
$$


Following the above conclusions the delay in the operation of the inverter should be adopted in the range

$$
\tau_{0} \in\left[0,3 T_{P W M}\right]
$$

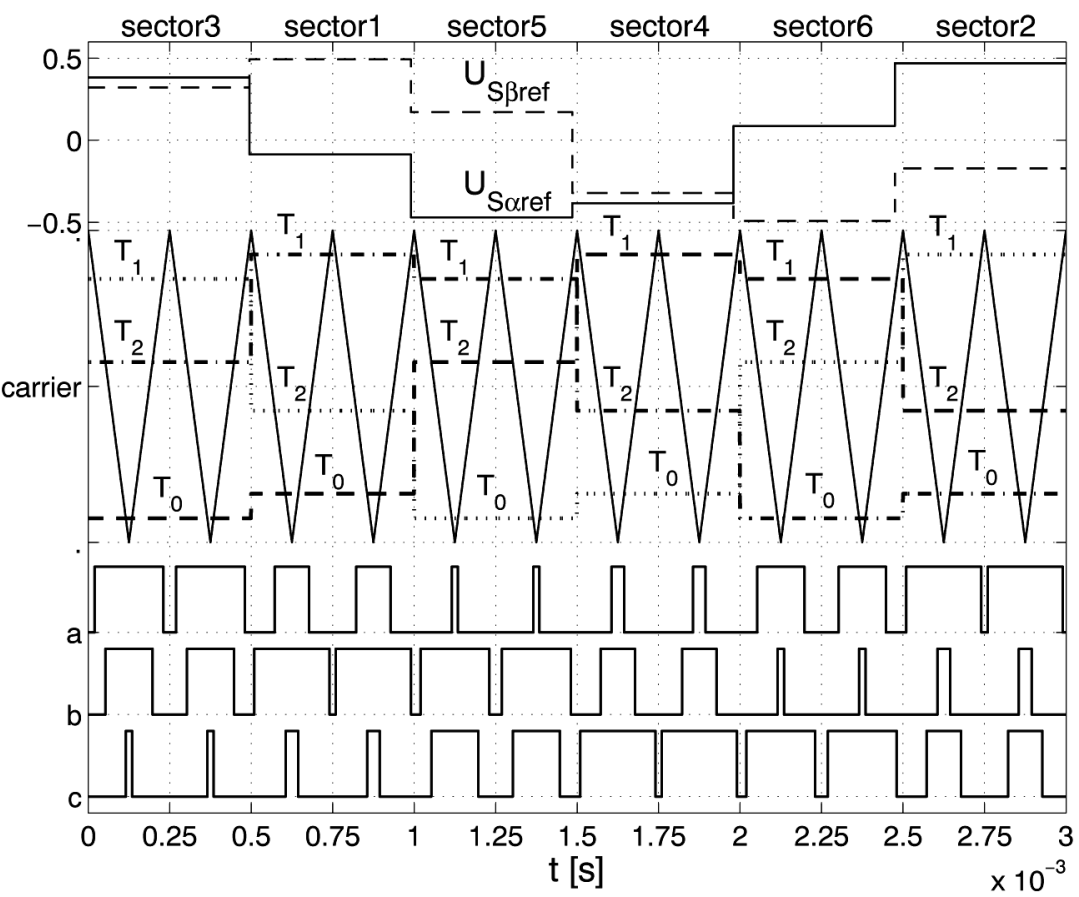

Fig. 6. SVM symmetrical signal $a, b, c$ generation (in p.u.) $\left(T_{P W M}=\frac{1}{4000} \mathrm{~s}\right)$

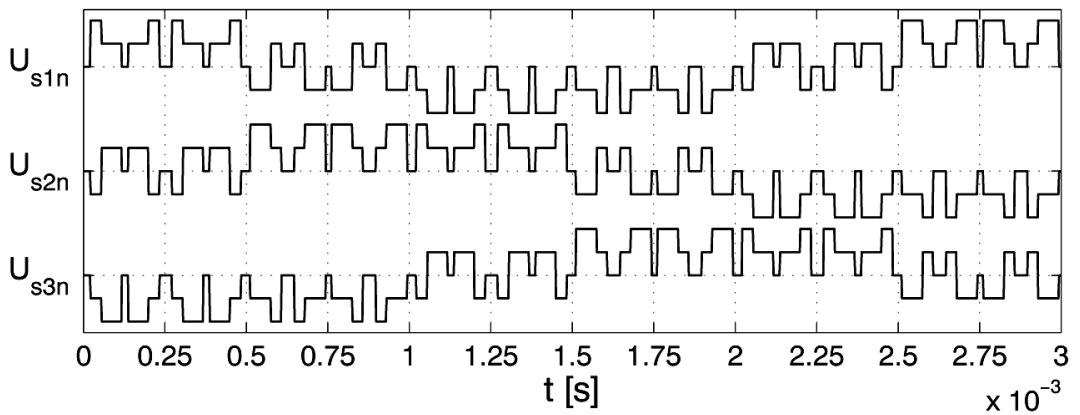

Fig. 7. Line to neutral output voltages for $\underline{U}_{S_{\text {ref }}}=0.9 U_{D C} e^{j\left(\frac{2 \pi}{9}+k \frac{\pi}{6}\right)}$ 


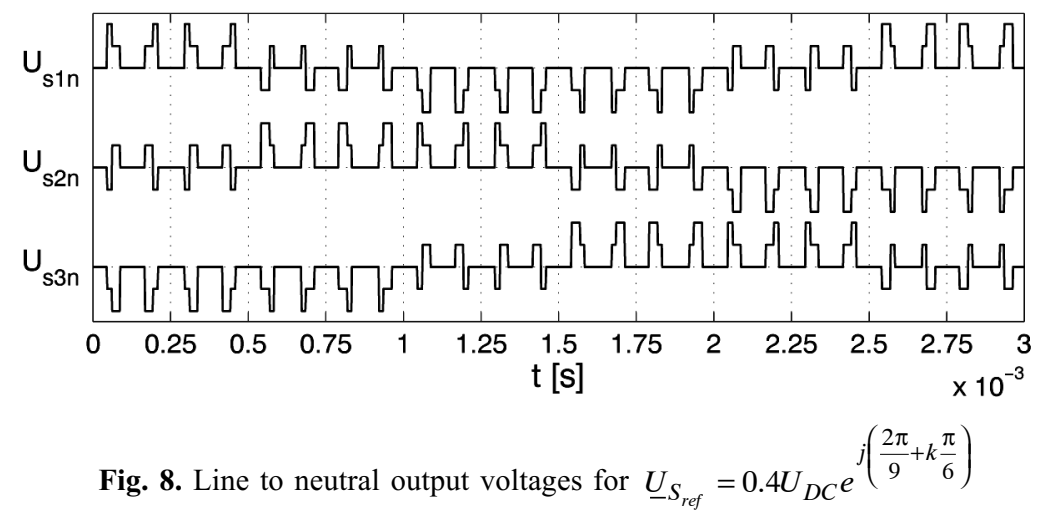

The voltage variations $U_{D C}$ on the capacitor $C=1000 \mu \mathrm{F}$ during the starting and braking PMSM are shown in Figure 9 (with active load torque).
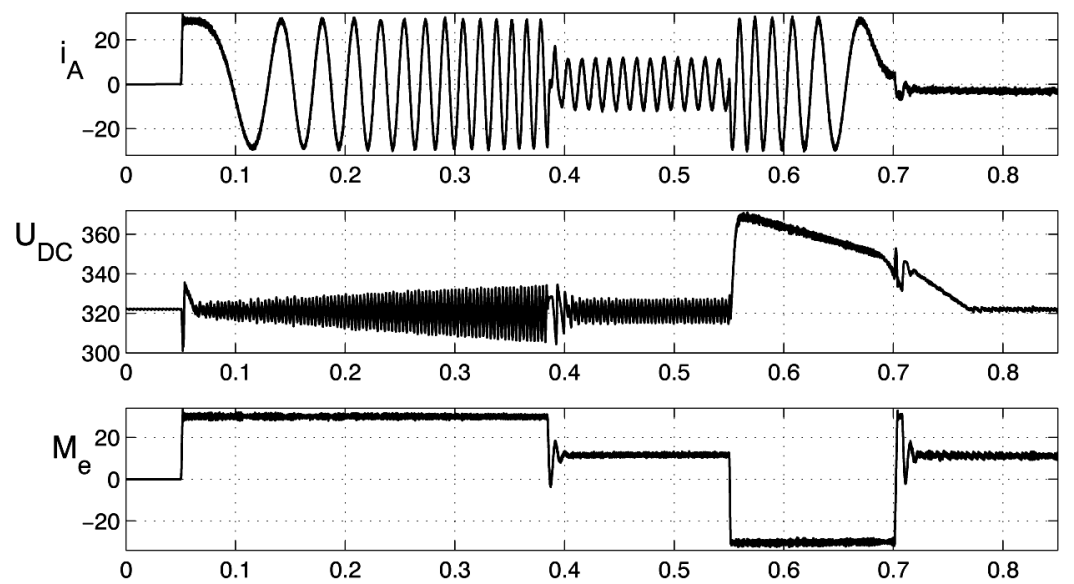

$\omega$

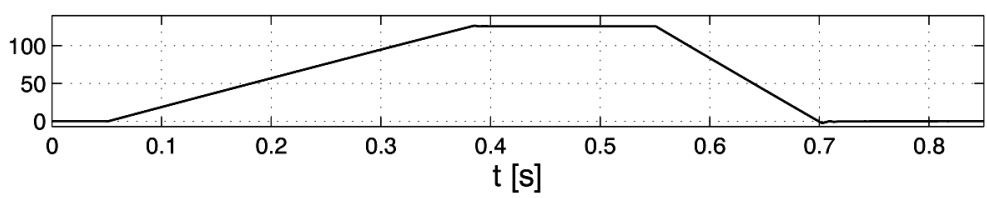

Fig. 9. The signals in PMSM control system $(2.3 \mathrm{~kW})$ without braking chopper

The changing signal of voltage $U_{D C}$ shows that it varies in the range from $302 \mathrm{~V}$ (for starting) to $370 \mathrm{~V}$ (for braking), however, the rated voltage is equal to $U_{D C_{N}}=325 \mathrm{~V}$. From this interval the range of variation of the inverter gain can be determined as

$$
K_{p} \in\left[K_{p_{\min }}, K_{p_{\max }}\right], \quad K_{p_{i}}=\frac{U_{D C_{i}}}{\max \left|\underline{U}_{S_{\text {ref }}}\right|}, \quad i=\max , \min
$$


On the basis of the assumptions (3), (4), (7), (8) adopted mathematical model as (1) taking account the changes in parameters

$$
G_{p}(s)=K_{p} e^{-\tau_{0} s}, \quad \tau_{0} \in\left[0, \tau_{\max }\right], \quad K_{p} \in\left[K_{p_{\min }}, K_{p_{\max }}\right]
$$

This model represents the typical parametric uncertainty (structured).

\section{Frequency Dependent Uncertainty}

The analysis of systems with parametric uncertainty (9) is possible however can be considered in the frequency domain (unstructured uncertainty), too.

In the uncertainty analysis of a plant the following descriptions are used [22]:

$\Pi$ : a set of possible perturbed plant models which is generated by $\mathcal{H}_{\infty}$ normbounded stable perturbations to the nominal plant. Usually this set includes an infinite number of possible models $G_{p}(s)$.

$\Pi_{f}:$ fixed or uncertain set of neglected dynamics.

$G_{0}(s) \in \Pi$ : nominal plant model.

$G_{p}(s) \in \Pi$ : particular perturbed plant model.

Multiplicative uncertainty $[8,22,24]$ is defined as:

$$
\text { П: } G_{p}(s)=G_{0}(s)\left(1+w_{I}(s) \Delta(s)\right), \quad\|\Delta\|_{\infty} \leq 1
$$

where $\Delta$ is a stable transfer-function and $w_{I}(s)$ is the input uncertainty weight.

If $G_{0}(s)$ is the certain model of the plant and $f(s)$ is neglected dynamics then $G_{p}(s)=G_{0}(s) f(s)$ is a set of plants and the relative uncertainty is defined by following relation

$$
l_{I}(\omega)=\max _{G_{p} \in \Pi}\left|\frac{G_{p}(j \omega)-G_{0}(j \omega)}{G_{0}(j \omega)}\right|=\max _{f \in \Pi_{f}}|f(j \omega)-1|
$$

The weight $w_{I}(s)$ is performed as a rational transfer-function

$$
\left|w_{I}(j \omega)\right| \geq l_{I}(\omega), \quad \forall \omega
$$

The weight $w_{I}(s)$ is the upper bound on the magnitude of $f(s)$, and is usually selected as $[1,22,24,18]$ :

$$
w_{I}(s)=\frac{\left(s+\omega_{B} A^{1 / n}\right)^{n}}{\left(\frac{s}{M^{1 / n}}+\omega_{B}\right)^{n}}
$$

where $\omega_{B}$ is bandwidth frequency, $A$ and $M$ are minimum and maximum of the magnitude plot of $|f(j \omega)-1|$. 


\section{Robust Performance}

The $\mathcal{L}_{2}$ (Euclidean) norm of a time-domain scalar signal $u(t)$ is defined as [8]

$$
\|u(t)\|_{2}=\sqrt{\int_{-\infty}^{\infty} u^{2}(t) d t}
$$

The norm (14) represents the energy of the signal $u$.

For stable scalar transfer-function $G(s)$ the $\mathcal{H}_{\infty}$ norm is defined as [8, 22, 24]

$$
\|G(s)\|_{\infty}=\sup _{\omega}|G(j \omega)|=\sup _{u \in \mathcal{L}^{2}} \frac{\|y(t)\|_{2}}{\|u(t)\|_{2}}, \quad \forall u \neq 0
$$

$\mathcal{H}_{\infty}$ norm for a SISO system is induced by $\mathcal{L}_{2}$ norm for signals. The physical interpretation of the $\mathcal{H}_{\infty}$ norm corresponds to the maximum energy amplification over the input signal. It can be shown that $\|G(s)\|_{\infty}$ equals the peak magnitude in the Bode plot of the transfer-function.

In a typical SISO closed-loop control system, with controller $G_{R}(s)$ and plant $G(s)$, important transfer-functions are defined:

$$
\begin{aligned}
& L=G G_{R} \quad \text { loop transfer-function } \\
& S=\frac{1}{1+L} \quad \text { sensitivity function } \\
& T=\frac{L}{1+L} \quad \text { complementary sensitivity function }
\end{aligned}
$$

They are indispensable to $\mathcal{H}_{\infty}$ optimization. In this approach the designer specifies the magnitude of suitable transfer-function as a function of frequency and then calculates a controller which gives the desired shape of the Bode plot [22]. In this approach the magnitude of the closed-loop transfer-function (sensitivity and complementary sensitivity function) is shaped. A synthesis of the controller is realized by the $\mathcal{H}_{\infty}$ performance index optimization.

Typically (nominal performance) in the loopshaping magnitude of $S$, which should be small, is only considered. The sensitivity function is compared with the upper bound $\frac{1}{w_{P}(s)}$ where $w_{P}$ is weight (fixed stable transfer-function). The loopshaping performance requirement is satisfied by condition

$$
|S(j \omega)|<\frac{1}{\left|w_{p}(j \omega)\right|}
$$


which in $\mathcal{H}_{\infty}$ norm leads to inequality

$$
\left\|w_{p}(s) S(s)\right\|_{\infty}<1
$$

The robust performance requires the loopshaping performance (19) to be satisfied for all possible plants (10). Thus, the optimization in $\mathcal{H}_{\infty}$ space $[1,8,22]$ leads to condition (20)

$$
\left\|\left|w_{p}(s) S(s)\right|+\left|w_{I}(s) T(s)\right|\right\|_{\infty}<1
$$

in which the transfer-functions $S, T$ are shaped by the controller parameters tuning.

\section{Numerical Example}

Considering the model (9) for the thyristor converter (Fig. 1) where time-delay equals $\tau_{\max }=8 \mathrm{~ms}$ and the parameters of the gain are

$$
\begin{aligned}
& K_{p_{\text {max }}}=84.5 \frac{\mathrm{V}}{\mathrm{V}}, \quad K_{p_{\text {min }}}=53.8 \frac{\mathrm{V}}{\mathrm{V}} \\
& K_{p a}=\frac{K_{p_{\max }}-K_{p_{\min }}}{2}, \quad K_{p r}=\frac{K_{p_{\max }}}{K_{p a}}
\end{aligned}
$$

From relation (11)

$$
l_{I}(\omega)=\max _{f \in \Pi_{f}}|f(j \omega)-1|=\left|K_{p r} e^{-\tau_{\max } s}-1\right|=\sqrt{K_{p r}^{2}-2 K_{p r} \cos \left(\omega \tau_{\max }\right)+1}
$$

the following parameters are calculated:

- $\omega_{\max }=\frac{\pi}{\tau_{\max }}$ frequency of the first maximum in the magnitude plot,

- $A=K_{p r}-1, M=K_{p r}+1$ minimum and maximum of the magnitude plot,

$-\omega_{B l}=\frac{1}{\tau_{\max }} \operatorname{arcos}\left(\frac{K_{p r}}{2}\right)$ bandwidth frequency $\left(l_{l}(\omega)=1\right)$.

The choice of weight is shown in Figure 10 which is completed by oscillatory element in the following form

$$
\omega_{I}(s)=\frac{s^{2}+\gamma s+\alpha}{\frac{1}{M} s^{2}+2 \frac{a}{\sqrt{M}} s+\beta}=M \frac{s^{2}+\gamma s+\alpha}{s^{2}+2 \xi \omega_{0} s+\omega_{0}^{2}}
$$

where $\xi \approx 0.8, \alpha=A \beta, a=\xi \sqrt{\beta}, \omega_{0}=\sqrt{M \beta}$. 


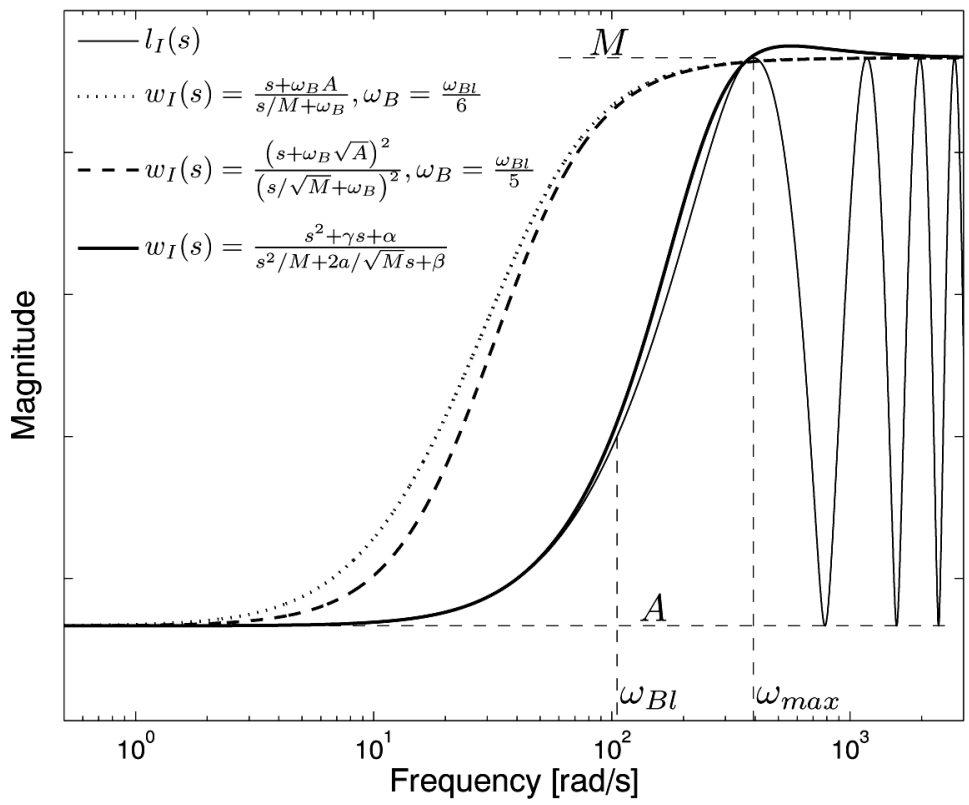

Fig. 10. Multiplicative weight for (21)

The coefficients $\beta$ and $\gamma$ are obtained by the parametric optimization (numericalmethods) for the following criterion

$$
\min _{\beta, \gamma}\left(\left|\omega_{I}(j \omega)\right|-l_{I}(\omega)\right)^{2}
$$

with the constraint $l_{I}(\omega) \leq\left|w_{I}(j \omega)\right|$.

The interior-point method (function fmincon in MATLAB) in the optimization problem is applied. Presented result with $10^{-6}$ absolute tolerance on the function value is obtained.

The minimization of $\mathcal{H}_{\infty}$ norm (20) for the motor torque controller is considered. The model of the power converter and DC motor [7, 11, 14, 20, 21] (fixed transfer-function) is assumed in the following form

$$
G(s)=\frac{I(s)}{U(s)}=\frac{K_{p a} \frac{B}{R} s}{B T s^{2}+B s+1}, \quad B=J \frac{R}{\psi_{e}^{2}}, \quad M_{e}=\psi_{e} I(s)
$$

where $B, \psi_{e}, M_{e}$ are electromechanical time constant, flux linkage, motor (electromagnetic) torque respectively. 
Proper operation of DC drive in dynamic states is guaranteed for the following limitations of the state variables:

$$
\left\{\begin{array}{l}
|I(t)| \leq I_{d}=\lambda_{N} I_{N}-\text { current limitation, } \\
\left|\frac{d I(t)}{d t}\right| \leq p I_{N} \quad-\text { limitation of current derivative }
\end{array}\right\}
$$

where $\lambda_{N}, p$ are positive constants.

Thus, the performance weight $w_{P}(s)$ must satisfy

$$
\left|\frac{s}{s+\frac{p}{\lambda_{N}}}\right|<\frac{1}{\left|w_{p}(s)\right|}
$$

so,

$$
w_{p}(s)=\frac{s / M_{1}+\omega_{B P}}{s+\omega_{B P} A_{1}}
$$

and for parameters of the drive from appendix $A$ the following parameters $A_{1}=0.01, M_{1}=1.55$, $\omega_{B P}=6 \mathrm{rad} / \mathrm{s}$ are proposed.

For parametric optimization of motor torque controller $G_{R}(s)$ the MATLAB function hinfstruct is applied. Hinfstruct is included in the Robust Control Toolbox and based on the paper [2]. The method uses subgradient calculus to solve the problem by first mini-mizing the spectral abscissa of the closed-loop system to find parameters for fixed-structure controllers.

For weights (22), (27) and fixed (certain) plant transfer-function (24) the parametric optimization of $\mathcal{H}_{\infty}$ norm (20) is considered. The input uncertainty weight $w_{I}(s)$ after parametric optimization includes the following coefficients: $\xi=0.79, \omega_{0}=245 \mathrm{rad} / \mathrm{s}, \alpha=13440, \gamma=585$.

From the fact that operator s occurs in the numerator of the motor transfer-function (24) the $\mathrm{II}^{2}$ controller is selected in the following form

$$
G_{R}(s)=\frac{K_{1}+K_{2} s}{s^{2}}
$$

Thus, for the plant $s G(s)$ and the PI controller parametric optimization is realized. In Figure 11 the results of numerical simulations are presented. The step response may be interpreted as p.u. transient. For too large value of the bandwidth frequency $\omega_{B P}$ the norm (20) is greater than 1 (Fig. 12), so optimization failed. For the compensator in the following form

$$
G_{R}(s)=\frac{b_{2} s^{2}+b_{1} s+b_{0}}{s\left(s^{2}+a_{1} s+a_{0}\right)}
$$

the proper solution of this problem may be obtained (Fig. 13). 

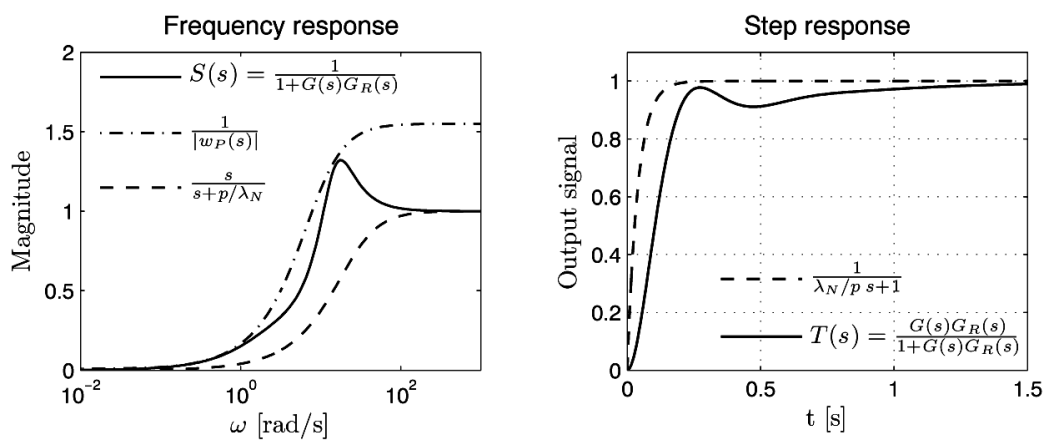

Fig. 11. Responses of the closed-loop system ( $\mathrm{I} \mathrm{I}^{2}$ controller $)-\mathrm{w}_{B P}=6 \mathrm{rad} / \mathrm{s}\left(G(s)=G_{0}(s)\right)$
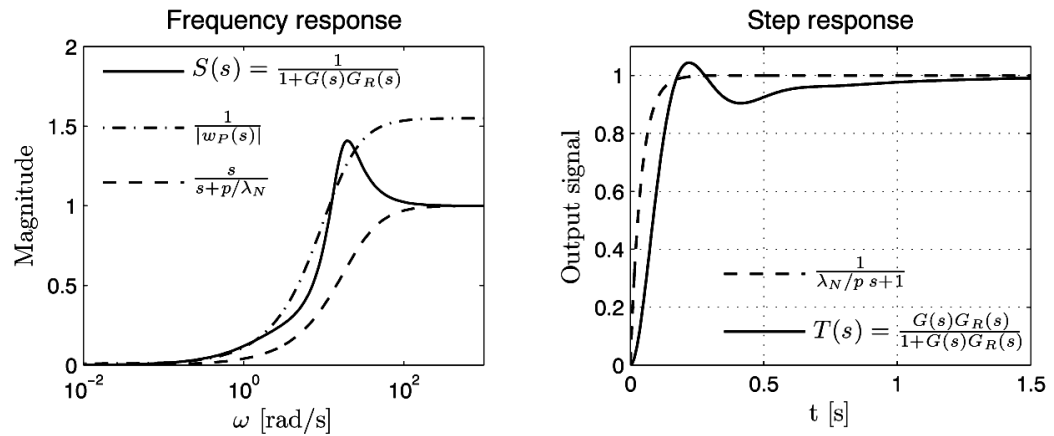

Fig. 12. Responses of the closed-loop system (I I $\mathrm{I}^{2}$ controller $)-\mathrm{w}_{B P}=9 \mathrm{rad} / \mathrm{s}\left(G(s)=G_{0}(s)\right)$
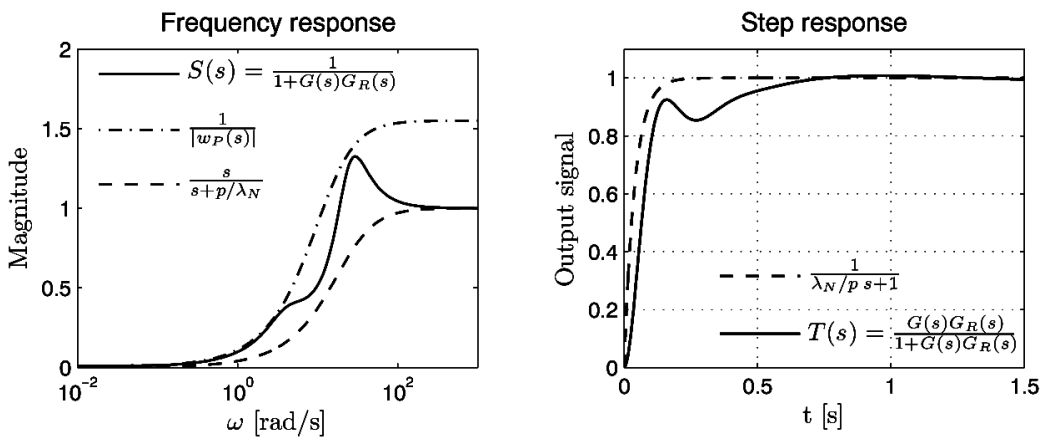

Fig. 13. Responses of closed-loop system (compensator) $-\mathrm{w}_{B P}=9 \mathrm{rad} / \mathrm{s}\left(G(s)=G_{0}(s)\right)$

\section{Conclusions}

The parameters uncertainty of the power supply of an electric motors is presented for the first time. The method of determining the parametric uncertainty of the thyristor-controlled converter and the voltage source inverter SVM is shown. 
The conversion method from the parametric to the dynamic uncertainty is used. The multiplicative uncertainty weight in the form of the oscillatory element is suggested.

In uncertainty conditions the motor torque controller synthesis in $\mathcal{H}_{\infty}$ space is achieved. In this approach the sensitivity upper bound is considered.

The results of the research in frequency- and time-domain are satisfied.

Obtained results are promising and one foresees them to complete with the uncertainty of the motor model.

Appendix A. DC Drive Parameters

$$
\begin{array}{lll}
P_{N}=18[\mathrm{~kW}], & U_{N}=440[\mathrm{~V}], & I_{N}=47[\mathrm{~A}], \\
n_{N}=1800[\mathrm{rpm}], & \omega_{N}=188\left[\frac{\mathrm{rad}}{\mathrm{s}}\right], & \omega_{0}=200.3\left[\frac{\mathrm{rad}}{\mathrm{s}}\right], \\
R=1.8[\Omega] & L=99[\mathrm{mH}], & T=L / R=55[\mathrm{~ms}], \\
\psi_{e N}=2.197\left[\frac{\mathrm{Vs}}{\mathrm{rad}}\right], & \lambda_{N}=2\left[\frac{I_{\max }}{I_{N}}\right], & J=0.69\left[\mathrm{kgm}^{2}\right], \\
K_{p}=69\left[\frac{\mathrm{V}}{\mathrm{V}}\right], & p=50 I_{N}\left[\frac{\mathrm{A}}{\mathrm{s}}\right] .
\end{array}
$$

\section{References}

[1] Ackermann J., Blue P., Robust control: the parameter space approach. London, Springer-Verlag, 2002.

[2] Apkarian P., Noll D., Nonsmooth $\mathcal{H}_{\infty}$ synthesis. IEEE Transaction on Automatic Control, 51(1): 2006, 71-86, .

[3] Bhattacharyya S.P., Chapellat H., Keel L.H., Robust Control: The Parametric Approach. NJ, Prentice Hall, 1995.

[4] Bisztyga K., Sterowanie i regulacja silników elektrycznych. Warszawa, WNT, 1989.

[5] Boldea I., Nasar S.A., Electric Drives. CRC Press, 1999.

[6] Bose B.K., Modern Power Electronics and AC Drives. NJ, Prentice Hall, 2002.

[7] Ciepiela A., Automatyka przeksztattnikowego napędu prądu statego. Kraków, Wydawnictwa AGH, 1992.

[8] Doyle J.C., Francis B., Tannenbaum A., Feedback Control Theory. Macmillan Publishing, 1990.

[9] Grabowski P., Stabilność układów Lurie. Kraków, Wydawnictwa AGH, 1999.

[10] Grzybowski W., Kardaszewicz J., Manitius J., Zygmunt H., Projektowanie przeksztaltników tyrystorowych. Warszawa, WNT, 1974.

[11] Kaźmierkowski M.P., Tunia H., Automatic Control of Converter-Fed Drives. Amsterdam, Elsevier, 1994.

[12] Kaźmierkowski M.P., Krishnan R., Blaabjerg F., Control in Power Electronics. Academic Press, San Diego, 2002. 
[13] Khalil H.K., Nonlinear Systems. NJ, Prentice Hall, 1996.

[14] Krishnan R., Electric Motor Drives. Modelling, Analysis and Control. NJ, Prentice Hall, 2001.

[15] Leonhard W., Control of Electrical Drives. Berlin, Springer-Verlag, 1997.

[16] Mitkowski W., Stabilizacja systemów dynamicznych. Warszawa, WNT, 1991.

[17] Mohan N., Undeland T.M., Power electronics: converters, applications, and design. Wiley, 2007.

[18] Piłat A., Włodarczyk P., The $\mu$-synthesis and analysis of the robust controller for the active magnetic levitation system. Automatyka (semi-annual AGH-UST), 15(1), 2011, 85-98.

[19] Piróg S., Energoelektronika: układy o komutacji sieciowej i o komutacji twardej. Kraków, Wydawnictwa AGH, 2006.

[20] Sieklucki G., Automatyka napędu. Kraków, Wydawnictwa AGH, 2009.

[21] Sieklucki G., Pole placement method for dc motor torque. Archives of Control Sciences, 19(3), 2009, 307-324.

[22] Skogestad S., Postlethwaite I., Multivariable feedback control: analysis and design. John Wiley, 2005.

[23] Texas Instruments. Implementation of a Speed Field Orientated Control of Three Phase AC Induction Motor using TMS320F240. Technical report, BPRA076, 1998.

[24] Zhou K., Doyle J.C., Essentials of Robust Control. NJ, Prentice Hall, 1998. 